\title{
Direct Synthesis of 5-Aryl Barbituric Acids by Rhodium(II)-Catalyzed Reactions of Arenes with Diazo Compounds**
}

\author{
Daniel Best, David J. Burns, and Hon Wai Lam*
}

\begin{abstract}
A commercially available rhodium(II) complex catalyzes the direct arylation of 5-diazobarbituric acids with arenes, allowing straightforward access to 5-aryl barbituric acids. Free $\mathrm{N}-\mathrm{H}$ groups are tolerated on the barbituric acid, with no complications arising from $\mathrm{N}-\mathrm{H}$ insertion processes. This method was applied to the concise synthesis of a potent matrix metalloproteinase (MMP) inhibitor.
\end{abstract}

Barbiturates have a long history in medicinal chemistry, having appeared in thousands of biologically active compounds since their emergence as sedatives and hypnotics at the turn of the 20 th century. ${ }^{[1]}$ More than 100 years after its introduction, phenobarbital (Figure 1) remains the most

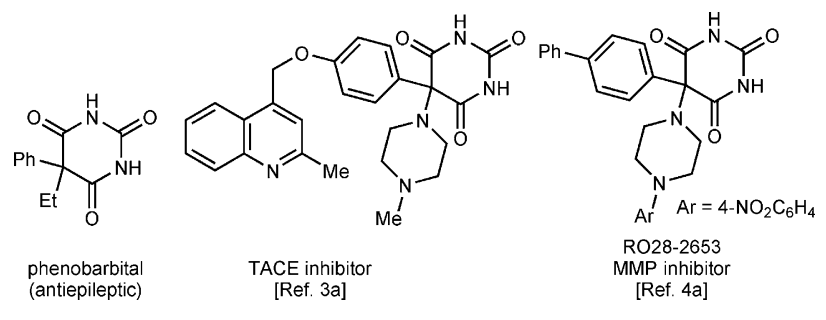

Figure 1. Biologically active 5 -aryl barbituric acids.

widely prescribed antiepileptic drug worldwide. ${ }^{[2]}$ 5-Aryl barbituric acids have received renewed interest owing to their ability to inhibit matrix metalloproteinases (MMPs) and the tumor necrosis factor alpha (TNF- $\alpha$ ) converting enzyme (TACE),${ }^{[3]}$ leading to their application in cancer treatment ${ }^{[4]}$ and in vivo imaging ${ }^{[5]}$ (Figure 1 ).

Our interest in 5-aryl barbituric acids stems from their suitability as substrates for $\mathrm{C}-\mathrm{H}$ functionalization; under ruthenium catalysis, they undergo oxidative annulation with alkynes to form spiroindenes ${ }^{[6]}$ The conventional approach to 5 -aryl barbituric acids is the condensation of ureas with 2-aryl malonic acids or esters ${ }^{[3 a, 4 a, e, 5 a, 7]}$ (Scheme 1a). ${ }^{[8]}$ In turn, 2-aryl

[*] Dr. D. Best, Dr. D. J. Burns, Prof. H. W. Lam School of Chemistry, University of Nottingham University Park, Nottingham, NG7 2RD (UK) E-mail: hon.lam@nottingham.ac.uk

[**] We thank the ERC (Starting Grant 258580) and the EPSRC (Leadership Fellowship to H.W.L.) for financial support.

$\square$ Supporting information for this article is available on the WWW under http://dx.doi.org/10.1002/anie.201502324.

of (c) 2015 The Authors. Published by Wiley-VCH Verlag GmbH \& Co. $\mathrm{KGaA}$. This is an open access article under the terms of the Creative Commons Attribution License, which permits use, distribution and reproduction in any medium, provided the original work is properly cited.

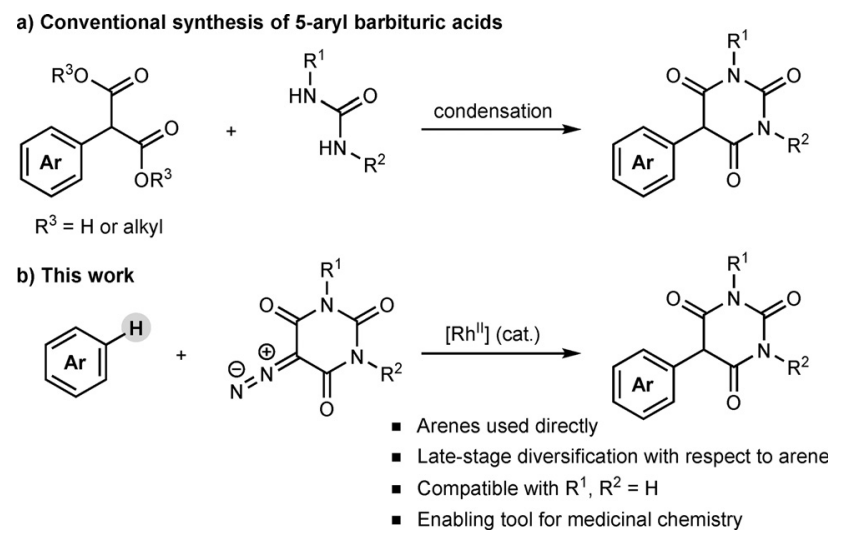

Scheme 1. Synthesis of 5-aryl barbituric acids.

malonic acids or esters can be prepared by palladium- ${ }^{[5 b, 9]}$ or copper-catalyzed $^{[10]}$ cross-couplings between malonates and haloarenes, or by alkoxycarbonylation of aryl acetate esters (which have limited commercial availability). ${ }^{[4 \mathrm{e}, 5 \mathrm{a}, 7 \mathrm{~b}]}$

Although we found that these condensation routes to 5-aryl barbituric acids were sometimes successful, they were incompatible with electron-deficient aryl groups owing to decarboxylation and other problematic side reactions. Furthermore, this early-stage diversification strategy is not ideal for library synthesis. Our attempts to develop a late-stage diversification approach by adapting existing malonatehaloarene cross-couplings ${ }^{[9,10]}$ to barbituric acids were unsuccessful because of poor reactivity. These limitations represent significant synthetic hurdles to compounds of considerable chemical and biological importance.

We envisioned an ideal strategy whereby a barbituric acid moiety would be coupled directly with arenes, without recourse to functional groups such as halides on the arene partner. As well as providing significantly improved access to useful substrates for $\mathrm{C}-\mathrm{H}$ functionalization, ${ }^{[6]}$ a more direct approach to 5-aryl barbituric acids would be a highly enabling tool for medicinal chemists. ${ }^{[1]}$ Herein, we report the efficient $\mathrm{Rh}^{\mathrm{II}}$-catalyzed direct arylation of 5-diazobarbituric acids with arenes at low catalyst loadings (Scheme $1 \mathrm{~b}$ ) and its application to the concise synthesis of an MMP inhibitor.

Prior to our investigations, the direct arylation of $\alpha$-diazocarbonyl compounds has shown promise. ${ }^{[12]}$ Whereas intramolecular $\mathrm{C}-\mathrm{H}$ insertion reactions of $\alpha$-diazocarbonyl compounds with arenes are well-known, ${ }^{[13]}$ intermolecular reactions are more challenging. The reaction of $\alpha$-diazoesters or $\alpha$-diazoketones with arenes under $\mathrm{Rh}^{\mathrm{II}}$ catalysis results in cycloheptatrienes, ${ }^{[14]}$ which can undergo an acid-catalyzed rearrangement to give products of net $\alpha$-arylation. ${ }^{[15]}$ More recent reports describe the arylation of $\alpha$-diazoesters or 
closely related compounds with (hetero)arenes under metal $^{[16-20]}$ or acid ${ }^{[21]}$ catalysis. However, the corresponding reactions of $\alpha$-diazo-1,3-dicarbonyl compounds are less common, ${ }^{[16 \mathrm{~d}, \mathrm{e}, 22,23]}$ and to the best of our knowledge, no reports of transition-metal-catalyzed couplings between 5diazobarbituric acids and arenes exist. ${ }^{[2]}$ Indeed, despite the biological significance of barbiturates, catalytic transformations of 5-diazobarbituric acids appear to be restricted to the cyclopropanation of styrenes. ${ }^{[25]}$ Interestingly, these reactions were conducted in fluorobenzene, but no products resulting from arene $\mathrm{C}-\mathrm{H}$ insertion were observed. ${ }^{[25]}$ Given these observations, the success of our proposed method was far from certain.

Fortunately, we discovered that just $0.1 \mathrm{~mol} \%$ of commercially available $\left[\mathrm{Rh}_{2}(\mathrm{esp})_{2}\right]^{[26]}$ smoothly catalyzed the coupling of 5-diazo-1,3-dimethylbarbituric acid (1a) with benzene at room temperature to give $\mathbf{2 a}$ in $77 \%$ yield (Scheme 2). ${ }^{[27]}$ Further studies showed that a range of monosubstituted arenes were tolerated $(\mathbf{2} \mathbf{b}-\mathbf{2} \mathbf{h})$. These reactions were performed with no precautions to exclude air or water, and the inexpensive arenes were used as the solvent. The products were formed with moderate to excellent regioselectivities and, with the exception of $\mathbf{2 b}$ and $\mathbf{2} \mathbf{k a}$, were isolated as mixtures of two regioisomers ${ }^{[28]}$ after chromatography. In most cases, recrystallization allowed for isolation of the pure para isomer (see the Supporting Information for details). Electron-rich arenes reacted with $\mathbf{1}$ a to provide $\mathbf{2} \mathbf{b}-\mathbf{2} \mathbf{d}$ in good yields. With toluene, no products from benzylic $\mathrm{C}-\mathrm{H}$ insertion were observed. ${ }^{[27]}$ Use of a small excess of anisole (1.2 equiv) resulted in a reduced (but synthetically useful) $64 \%$ yield of $\mathbf{2 c}$ owing to a lower conversion, attributable to inefficient mixing of the reagents. Fluorobenzene reacted smoothly to give $\mathbf{2 f}$ in $78 \%$ yield, further demonstrating that relatively electron-neutral arenes (Hammett constant $\sigma_{\mathrm{p}}$ of F: 0.06$)^{[29]}$ are effective. Chloro- and bromobenzene were also surprisingly effective $(\mathbf{2} \mathbf{g}$ and $\mathbf{2} \mathbf{h})$, despite being deactivated substrates $\left(\sigma_{\mathrm{p}}\right.$ of $\mathrm{Cl}$ and $\left.\mathrm{Br}: 0.23\right){ }^{[29]}$ Even trifluoromethoxybenzene $\left(\sigma_{\mathrm{p}} \text { of } \mathrm{OCF}_{3}: 0.35\right)^{[29]}$ gave $\mathbf{2 e}$ in good yield, albeit in a 4:1 regioisomeric ratio. Arenes with meta-directing substituents, such as $\mathrm{CF}_{3}, \mathrm{CN}, \mathrm{CO}_{2} \mathrm{Me}$, or $\mathrm{NO}_{2}$ groups, were unsuitable, but disubstituted arenes, such as meta-xylene and 1,3-dimethoxybenzene, reacted with $\mathbf{1}$ a to give $\mathbf{2} \mathbf{i}$ and $\mathbf{2} \mathbf{j}$ in high regioselectivities. The reactions of ortho-xylene and 1,2-dimethoxybenzene were high-yielding, but less regioselective (2 ka and $\mathbf{2 1}$ ). With ortho-xylene, the minor regioisomer $\mathbf{2} \mathbf{k b}$ (see the Supporting Information for the structure) was also isolated in $14 \%$ yield. 1-Methylindole reacted smoothly to give 5-(3-indolyl)barbituric acid $\mathbf{3}$ in $73 \%$ yield [Eq. (1)]. ${ }^{[16]}$

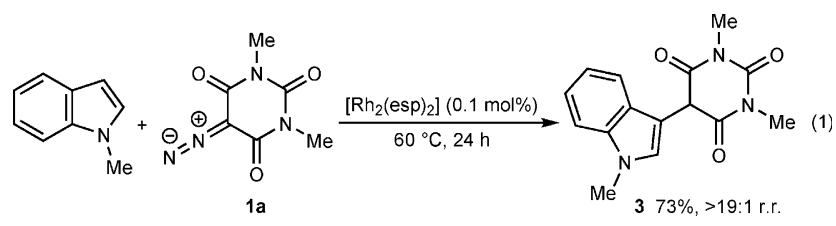

Our focus now turned to the variation of the 5-diazobarbituric acid (Table 1). The first question to address was
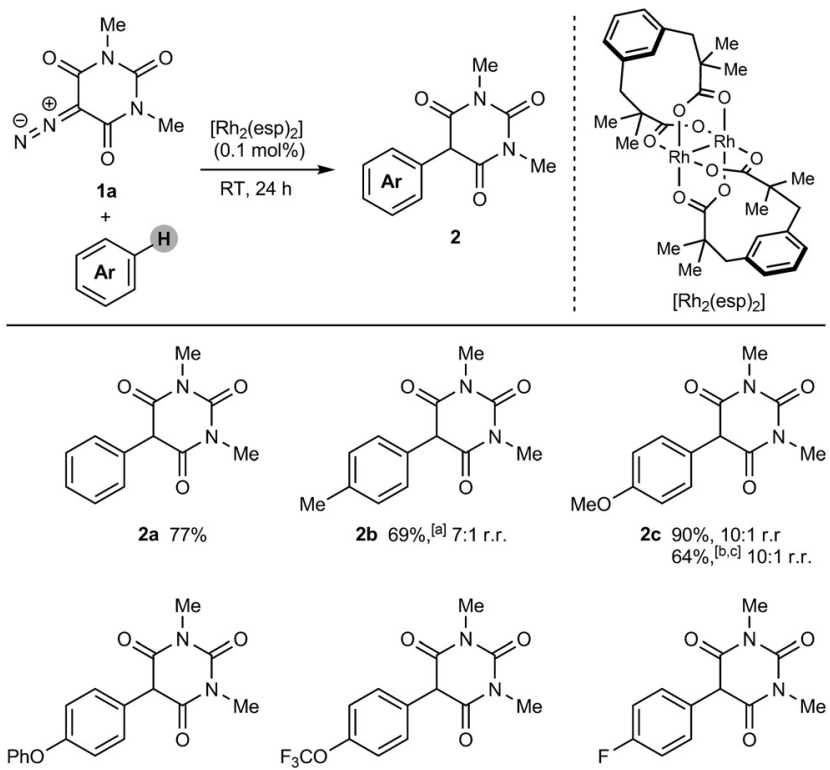

2d $86 \%$, [d,e] $15: 1$ r.r.

2e $68 \%, 4: 1$ r.r.

2f $78 \%, 9: 1$ r.r.<smiles>CN1C(=O)C(c2ccc(Cl)cc2)C(=O)N(C)C1=O</smiles><smiles>CN1C(=O)C(c2ccc(Br)cc2)C(=O)N(C)C1=O</smiles><smiles>Cc1ccc(C2C(=O)N(C)C(=O)N(C)C2=O)c(C)c1</smiles><smiles>COc1ccc(C2C(=O)N(C)C(=O)N(C)C2=O)c(OC)c1</smiles><smiles>[Y4]N1C(=O)C(c2ccc(C)c(C)c2)C(=O)N(O)C1=O</smiles><smiles>COc1ccc(C2C(=O)N(C)C(=O)N(C)C2=O)cc1OC</smiles>

Scheme 2. Rhodium(II)-catalyzed arylation of 5-diazobarbituric acid 1 a. Reactions were conducted with $2.00 \mathrm{mmol}$ of $1 \mathrm{a}$ in $2.0 \mathrm{~mL}$ of the arene. r.r. = regioisomeric ratio as determined by ${ }^{1} \mathrm{H}$ NMR analysis of the unpurified reaction mixture. Yields are of isolated mixtures of inseparable regioisomers in the same ratio as in the unpurified mixtures. [a] Isolated as a single regioisomer. [b] Conducted with $3.00 \mathrm{mmol}$ of $1 \mathrm{a}$ and $3.60 \mathrm{mmol}$ of anisole. [c] Isolated as a 15:1 mixture of regioisomers. [d] Conducted with $1.00 \mathrm{mmol}$ of $1 \mathrm{a}$ in $1.0 \mathrm{~mL}$ of the arene. [e] Conducted at $30^{\circ} \mathrm{C}$ for $7 \mathrm{~h}$. [f] Isolated as a 10:1 mixture of regioisomers. [g] The minor isomer $\mathbf{2} \mathbf{k b}$ was isolated in $14 \%$ yield.

whether $\mathrm{N}$ alkylation is essential, given that most biologically active barbiturates are not 1,3-dialkylated, and free $\mathrm{N}-\mathrm{H}$ groups might be expected to undergo insertion reactions with a rhodium carbenoid. Remarkably, this concern was unwarranted; 5-diazo-1-methylbarbituric acid $\mathbf{1 b}$ reacted with anisole to provide $4 \mathbf{a}$ in $68 \%$ yield (entry 1 ), whereas 5-diazobarbituric acid $\mathbf{1 c}$, which bears two free $\mathrm{N}-\mathrm{H}$ groups, gave $\mathbf{4 b}$ in $93 \%$ yield (entry 2). Coupling of $\mathbf{1} \mathbf{c}$ with diphenyl ether using $0.25 \mathrm{~mol} \%$ of $\left[\mathrm{Rh}_{2}(\mathrm{esp})_{2}\right]$ at $120^{\circ} \mathrm{C}$ gave $4 \mathbf{c}$ in excellent yield with good isomeric purity. Compound $\mathbf{4 c}$ is an important precursor to biologically active barbitur-

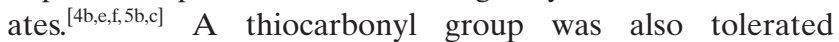
(entry 4), but our conditions did not provide good results when applied to other $\alpha$-diazo-1,3-dicarbonyl compounds. ${ }^{[30]}$

To further demonstrate the advantages of our method, we synthesized the potent and selective MMP inhibitor $8\left(\mathrm{IC}_{50}\right.$ : 
Table 1: Rhodium(II)-catalyzed arylation of various 5-diazobarbituric acids. ${ }^{[a]}$

$$
\text { Entry Product }
$$$$
\text { (1) }
$$

[a] Reactions were conducted with $0.50 \mathrm{mmol}$ of $1 \mathrm{~b}-1 \mathrm{e}$ in $0.5 \mathrm{~mL}$ of the arene. [b] Yield of isolated inseparable mixtures of regioisomers in the same ratio as in the unpurified reaction mixtures. [c] Regioisomeric ratio as determined by ${ }^{1} \mathrm{H}$ NMR analysis of the unpurified reaction mixtures. [d] Isolated as a single regioisomer. [e] Conducted with $1.00 \mathrm{mmol}$ of $1 \mathrm{c}$ and $1.0 \mathrm{~mL}$ of anisole. [f] Conducted with $0.25 \mathrm{~mol} \%$ of $\left[\mathrm{Rh}_{2}(\mathrm{esp})_{2}\right]$.

1 nM vs. MMP-9 with 26-fold selectivity over MMP-2;[5a] Scheme 3). The $\mathrm{Rh}^{\mathrm{II}}$-catalyzed reaction of diazobarbituric acid 1c with 4-bromophenyl phenyl ether occurred at the

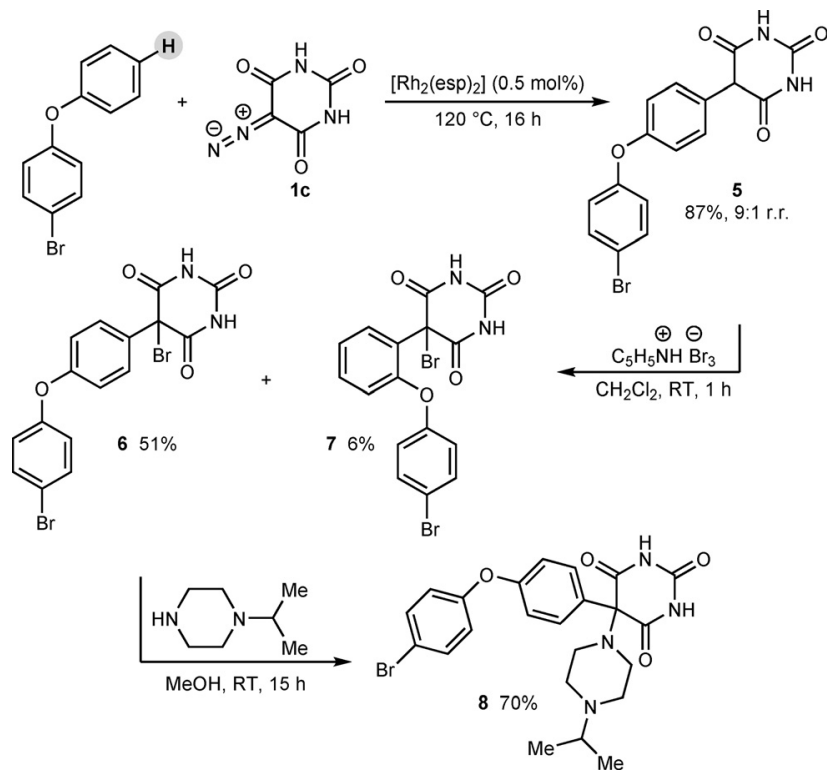

Scheme 3. Synthesis of MMP-9 inhibitor 8. most sterically accessible site, with no evidence of reaction at the 4-bromophenyl ring, to give 5-aryl barbituric acid $\mathbf{5}$ in $87 \%$ yield and a regioisomeric ratio of 9:1. This compound was previously accessed in six steps from commercial materials in $37 \%$ overall yield ${ }^{[5 a]}$ which highlights the brevity of our approach. Bromination at the C5 position with pyridinium tribromide provided the readily separable isomers $6(51 \%)$ and $7(6 \%) \cdot{ }^{[31]}$ Displacement of the bromide of 6 with $N$-isopropylpiperazine then gave MMP inhibitor 8 in $70 \%$ yield. $^{[5 \mathrm{a}]}$

Finally, $\left[\mathrm{Rh}_{2}(\mathrm{esp})_{2}\right]$ also efficiently catalyzes $\mathrm{C}\left(\mathrm{sp}^{3}\right)-\mathrm{H}$ insertion reactions in the absence of arenes; ${ }^{[32]}$ alkylation of 1a with cyclohexane proceeded smoothly to form 9 in $83 \%$ yield [Eq. (2)].

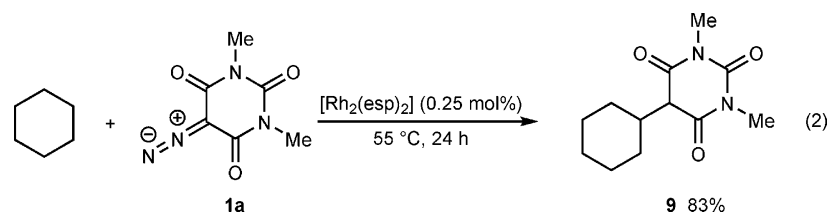

In conclusion, the coupling of arenes with 5-diazobarbituric acids proceeds efficiently under $\mathrm{Rh}^{\mathrm{II}}$ catalysis to provide medicinally important compounds in a direct manner that is more suited to drug discovery than existing technologies. The method is compatible with free $\mathrm{N}-\mathrm{H}$ groups on the barbituric acids, with no complications arising from $\mathrm{N}-\mathrm{H}$ insertion processes. The operational simplicity, mild conditions, and low loading of a commercially available catalyst further increase the appeal of this method.

Keywords: arylation · barbituric acid · carbenes . diazo compounds $\cdot$ rhodium

How to cite: Angew. Chem. Int. Ed. 2015, 54, 7410-7413 Angew. Chem. 2015, 127, 7518-7521

[1] a) J. T. Bojarski, J. L. Mokrosz, H. J. Barton, M. H. Paluchowska, Adv. Heterocycl. Chem. 1985, 38, 229-297; b) F. López-Muñoz, R. Ucha-Udabe, C. Alamo, Neuropsychiatr. Dis. Treat. 2005, 1, $329-343$; c) W. Löscher, M. A. Rogawski, Epilepsia 2012, 53, $12-25$.

[2] a) Z. Yasiry, S. D. Shorvon, Epilepsia 2012, 53, 26-39; b) M. J. Brodie, P. Kwan, Epilepsia 2012, 53, 40-46.

[3] a) J. J. W. Duan, Z. Lu, Z. R. Wasserman, R.-Q. Liu, M. B. Covington, C. P. Decicco, Bioorg. Med. Chem. Lett. 2005, 15, 2970 -2973; b) S. DasGupta, P. R. Murumkar, R. Giridhar, M. R. Yadav, Bioorg. Med. Chem. 2009, 17, 444-459.

[4] a) F. Grams, H. Brandstetter, D. A. Simonetta, D. Geppert, H.W. Krell, H. Leinert, V. Livi, E. Menta, A. Oliva, G. Zimmermann, Biol. Chem. 2001, 382, 1277-1285; b) L. H. Foley, R. Palermo, P. Dunten, P. Wang, Bioorg. Med. Chem. Lett. 2001, 11, 969-972; c) H. Brandstetter, F. Grams, D. Glitz, A. Lang, R. Huber, W. Bode, H.-W. Krell, R. A. Engh, J. Biol. Chem. 2001, 276, 17405-17412; d) E. Maquoi, N. E. Sounni, L. Devy, F. Olivier, F. Frankenne, H.-W. Krell, F. Grams, J.-M. Foidart, A. Noël, Clin. Cancer Res. 2004, 10, 4038-4047; e) J. Wang, C. Medina, M. W. Radomski, J. F. Gilmer, Bioorg. Med. Chem. 2011, 19, 4985-4999; f) J. Wang, S. O’Sullivan, S. Harmon, R. Keaveny, M. W. Radomski, C. Medina, J. F. Gilmer, J. Med. Chem. 2012, 55, 2154-2162; g) J. Wang, M. W. Radomski, C. 
Medina, J. F. Gilmer, Bioorg. Med. Chem. Lett. 2013, 23, $444-$ 447.

[5] a) H.-J. Breyholz, M. Schäfers, S. Wagner, C. Höltke, A. Faust, H. Rabeneck, B. Levkau, O. Schober, K. Kopka, J. Med. Chem. 2005, 48, 3400-3409; b) H.-J. Breyholz, S. Wagner, A. Faust, B. Riemann, C. Höltke, S. Hermann, O. Schober, M. Schäfers, K. Kopka, ChemMedChem 2010, 5, 777-789; c) D. Schrigten, H.-J Breyholz, S. Wagner, S. Hermann, O. Schober, M. Schäfers, G. Haufe, K. Kopka, J. Med. Chem. 2012, 55, 223-232.

[6] S. Reddy Chidipudi, I. Khan, H. W. Lam, Angew. Chem. Int. Ed. 2012, 51, 12115-12119; Angew. Chem. 2012, 124, 12281-12285.

[7] a) V. Lapachev, W. Stadlbauer, T. Kappe, Monatsh. Chem. 1988 119, 97-102; b) A. R. Daniewski, W. Liu, M. Okabe, Org. Process Res. Dev. 2004, 8, 411-414.

[8] For an approach involving the condensation with carbodiimides, see: A. Volonterio, M. Zanda, J. Org. Chem. 2008, 73, 74867497.

[9] a) N. A. Beare, J. F. Hartwig, J. Org. Chem. 2002, 67, 541-555; b) S. Hutchings, W. Liu, R. Radinov, Heterocycles 2006, 67, $763-$ 768.

[10] a) E. J. Hennessy, S. L. Buchwald, Org. Lett. 2002, 4, 269-272; b) X. Xie, G. Cai, D. Ma, Org. Lett. 2005, 7, 4693-4695.

[11] The arylation of 5-alkyl barbituric acids with diaryl iodonium reagents has been reported, but we found this approach to be unsuccessful using 5-unsubstituted barbituric acids; see: P. Y. Savechenkov, X. Zhang, D. C. Chiara, D. S. Stewart, R. Ge, X Zhou, D. E. Raines, J. B. Cohen, S. A. Forman, K. W. Miller, K. S. Bruzik, J. Med. Chem. 2012, 55, 6554-6565.

[12] For the non-direct arylation of $\alpha$-diazocarbonyl compounds with aryl boronic acids or aryl siloxanes, see: a) C. Peng, Y. Wang, J. Wang, J. Am. Chem. Soc. 2008, 130, 1566-1567; b) Y.-T. Tsoi, Z. Zhou, A. S. C. Chan, W.-Y. Yu, Org. Lett. 2010, 12, 4506-4509; c) Y.-T. Tsoi, Z. Zhou, W.-Y. Yu, Org. Lett. 2011, 13, 5370-5373; d) Y. Xia, Z. Liu, S. Feng, F. Ye, Y. Zhang, J. Wang, Org. Lett. 2015, 17, $956-959$.

[13] For representative examples, see: a) M. P. Doyle, M. S. Shanklin, H. Q. Pho, S. N. Mahapatro, J. Org. Chem. 1988, 53, 1017-1022; b) D. S. Brown, M. C. Elliott, C. J. Moody, T. J. Mowlem, J. P. Marino, Jr., A. Padwa, J. Org. Chem. 1994, 59, 2447-2455; c) H. Tsutsui, Y. Yamaguchi, S. Kitagaki, S. Nakamura, M. Anada, S. Hashimoto, Tetrahedron: Asymmetry 2003, 14, 817-821.

[14] a) A. J. Anciaux, A. Demonceau, A. F. Noels, A. J. Hubert, R. Warin, P. Teyssie, J. Org. Chem. 1981, 46, 873-876; b) T. Ye, M. A. McKervey, Chem. Rev. 1994, 94, 1091-1160.

[15] M. A. McKervey, D. N. Russell, M. F. Twohig, J. Chem. Soc. Chem. Commun. 1985, 491-492.

[16] For metal-catalyzed reactions of $\alpha$-diazoesters with indoles, see: a) W.-W. Chan, S.-H. Yeung, Z. Zhou, A. S. C. Chan, W.-Y. Yu, Org. Lett. 2010, 12, 604-607; b) T. Goto, Y. Natori, K. Takeda, H. Nambu, S. Hashimoto, Tetrahedron: Asymmetry 2011, 22, 907-915; c) Y. Cai, S.-F. Zhu, G.-P. Wang, Q.-L. Zhou, $A d v$. Synth. Catal. 2011, 353, 2939-2944; d) J. M. Fraile, K. Le Jeune, J. A. Mayoral, N. Ravasio, F. Zaccheria, Org. Biomol. Chem. 2013, 11, 4327-4332; e) I. E. Tsyshchuk, D. V. Vorobyeva, A. S. Peregudov, S. N. Osipov, Eur. J. Org. Chem. 2014, 2480-2486; see also: f) Y. Lian, H. M. L. Davies, Org. Lett. 2012, 14, 1934 1937.

[17] For copper-catalyzed reactions of $\alpha$-diazoesters with electronrich arenes, see: a) E. Tayama, T. Yanaki, H. Iwamoto, E. Hasegawa, Eur. J. Org. Chem. 2010, 6719-6721; b) E. Tayama, M. Ishikawa, H. Iwamoto, E. Hasegawa, Tetrahedron Lett. 2012, $53,5159-5161$.

[18] For gold-catalyzed reactions of $\alpha$-diazoesters with arenes, see: a) I. Rivilla, B. P. Gómez-Emeterio, M. R. Fructos, M. M. Díaz Requejo, P. J. Pérez, Organometallics 2011, 30, 2855-2860; b) Z.
Yu, B. Ma, M. Chen, H.-H. Wu, L. Liu, J. Zhang, J. Am. Chem. Soc. 2014, 136, 6904-6907; c) Y. Xi, Y. Su, Z. Yu, B. Dong, E. J. McClain, Y. Lan, X. Shi, Angew. Chem. Int. Ed. 2014, 53, $9817-$ 9821; Angew. Chem. 2014, 126, 9975-9979.

[19] For examples of rhodium(II)-catalyzed arylations of $\alpha$-diazoesters with subsequent electrophile trapping, see: a) H. Qiu, M. Li, L.-Q. Jiang, F.-P. Lv, L. Zan, C.-W. Zhai, M. P. Doyle, W.-H. Hu, Nat. Chem. 2012, 4, 733-738; b) S. Jia, D. Xing, D. Zhang, W. Hu, Angew. Chem. Int. Ed. 2014, 53, 13098-13101; Angew. Chem. 2014, 126, 13314-13317.

[20] For copper-catalyzed reactions of diazo compounds with polyfluoroarenes, see: S. Xu, G. Wu, F. Ye, X. Wang, H. Li, X. Zhao, Y. Zhang, J. Wang, Angew. Chem. Int. Ed. 2015, 54, 4669-4672; Angew. Chem. 2015, 127, 4752-4755.

[21] For trifluoromethanesulfonic acid catalyzed reactions of 3diazooxindoles with arenes, see: C. Zhai, D. Xing, C. Jing, J. Zhou, C. Wang, D. Wang, W. Hu, Org. Lett. 2014, 16, $2934-2937$.

[22] a) M. Toda, M. Hattori, K. Okada, M. Oda, Chem. Lett. 1987, 1263 -1266; b) M. J. Rosenfeld, B. K. R. Shankar, H. Shechter, J. Org. Chem. 1988, 53, 2699-2705; c) S. V. Chapyshev, H. Nakano, T. Ibata, Russ. Chem. Bull. 1996, 45, 471-473; d) M. Yang, T. R. Webb, P. Livant, J. Org. Chem. 2001, 66, 4945-4949; e) L. Goldoni, G. Cravotto, A. Penoni, S. Tollari, G. Palmisano, Synlett 2005, 927-930; f) M. B. Johansen, M. A. Kerr, Org. Lett. 2010, $12,4956-4959$

[23] The arylation of $\alpha$-diazomalonates and related compounds has also been achieved by rhodium(III)-catalyzed ortho-directed C-H functionalization; see: a) W.-W. Chan, S.-F. Lo, Z. Zhou, W.-Y. Yu, J. Am. Chem. Soc. 2012, 134, 13565-13568; b) X. Yu, S. Yu, J. Xiao, B. Wan, X. Li, J. Org. Chem. 2013, 78, 5444-5452.

[24] For the photolytic coupling of 1,3-dicyclohexyl-5-diazobarbituric acid with benzene as one of several side reactions, see: M. Ulbricht, G. Tomaschewski, J. U. Thurner, J. Prakt. Chem. 1989, $331,873-877$

[25] X. Wang, Y. R. Lee, Bull. Korean Chem. Soc. 2013, 34, 17351740.

[26] C. G. Espino, K. W. Fiori, M. Kim, J. Du Bois, J. Am. Chem. Soc. 2004, 126, 15378-15379.

[27] $\left[\mathrm{Rh}_{2}(\mathrm{OAc})_{4}\right], \quad\left[\mathrm{Rh}_{2}\left(\mathrm{O}_{2} \mathrm{CCPh}_{3}\right)_{4}\right], \quad\left[\mathrm{Rh}_{2}\left\{\mathrm{O}_{2} \mathrm{C}\left(n \mathrm{C}_{7} \mathrm{H}_{15}\right)\right\}_{4}\right]$, $\left[\mathrm{Rh}_{2}(\mathrm{OPiv})_{4}\right], \quad\left[\mathrm{Rh}_{2}\left\{\mathrm{O}_{2} \mathrm{C}\left(n \mathrm{C}_{3} \mathrm{~F}_{7}\right)\right\}_{4}\right]$, and $\left[\mathrm{Rh}_{2}\{(S) \text {-TFPTTL }\}_{4}\right]$ were also evaluated in the arylation of $\mathbf{1}$ a with toluene. Except for $\left[\operatorname{Rh}_{2}\{(S) \text {-TFPTTL }\}_{4}\right]$, these gave inferior results. See the Supporting Information for full details.

[28] For $\mathbf{2 b}-\mathbf{2 h}$, we believe the minor regioisomer to be the 1,2disubstituted arene, based on the isolation of $\mathbf{7}$ (Scheme 3).

[29] C. Hansch, A. Leo, R. W. Taft, Chem. Rev. 1991, 91, 165-195.

[30] Cyclic 2-diazo-1,3-diones gave complex mixtures (see Ref. [22b,c]) whereas 3-diazobenzopyran-2,4(3H)-dione underwent successful arylation at room temperature, but with poor regioselectivities compared with Ref. [22e]. The 2-diazo derivative of Meldrum's acid appeared to react well, but decomposition of the arylation products during chromatography prevented their clean isolation.

[31] The use of $N$-bromosuccinimide (NBS) and $\mathrm{BzOOBz}_{\text {in }} \mathrm{CCl}_{4}$ or $\mathrm{Br}_{2}$ and $\mathrm{HBr}$ in $\mathrm{AcOH}$ gave yields of $52 \%$ and $56 \%$, respectively, for the same reaction; see Ref. [5a].

[32] For reviews on $\mathrm{C}\left(\mathrm{sp}^{3}\right)-\mathrm{H}$ insertion reactions with rhodium(II) carbenoid complexes, see: a) H. M. L. Davies, J. R. Manning, Nature 2008, 451, 417-424; b) H. M. L. Davies, D. Morton, Chem. Soc. Rev. 2011, 40, 1857-1869.

Received: March 17, 2015

Published online: May 8, 2015 